JERÔNIMO \& CÂMARA, v(10), no 10, p. 2165-2174, JAN-ABR, 2013.

Rev. Elet. em Gestão, Educação e Tecnologia Ambiental (e-ISSN: 2236-1170)

\title{
AS CONSEQUÊNCIAS SÓCIO-AMBIENTAIS DECORRENTES DO DESCARTE INADEQUADO DOS RESÍDUOS SÓLIDOS NO MUNICÍPIO DE BREJINHO-RN
}

\section{SOCIAL AND ENVIRONMENTAL CONSEQUENCES AS DUE TO THE IMPROPER DISPOSAL OF SOLID WASTE IN THE CITY OF BREJINHO-RN}

\author{
Carlos Enrique de M. Jerônimo', Simone Pereira da Câmara² \\ ${ }^{1}$ Doutorado em Engenharia Quimica. Engenheiro de Processamento de Petroleo da Petrobras. \\ c enrique@hotmail.com \\ ${ }^{2}$ Especialista em Gestao e Pericia Ambiental. simonecamara@hotmail.com
}

http://dx.doi.org/10.5902/223611707681

\begin{abstract}
RESUMO
Em pleno século XXI, um dos maiores desafios relacionados ao meio ambiente com que se defronta a sociedade moderna é o equacionamento da questão dos resíduos sólidos, os grandes centros urbanos estão convivendo com uma série de problemas estruturais, e o êxodo dos habitantes, da zona rural, tem influído no seu crescimento demográfico, o que acaba agravando as condições ambientais da população. Estudo sistematizado das áreas críticas com resíduos sólidos no Município de Brejinho-RN, propõe apresentar através de dados quantitativos e qualitativos, os pontos críticos de insalubridade neste Município. Os dados foram obtidos através de relatórios de pesquisas e visitas técnicas. Constatou-se desta forma a falta de educação ambiental da população, principalmente aquela de baixo poder sócio econômico instalada nas áreas mais críticas como: nos assentamentos e no meio rural.
\end{abstract}

Palavras-chave: riscos ambientais, água produzida e irrigação.

\begin{abstract}
In the XXI century, one of the biggest environmental challenges facing modern society is addressing the issue of solid waste, the major urban centers are struggling with a number of structural problems, and the exodus of the inhabitants of rural, has influenced on its population growth, which ultimately exacerbating the environmental conditions of the population. Systematic study of critical areas with solid waste in the City of Brejinho-RN, proposes to present through quantitative and qualitative data, the critical points of this unhealthy city. Data were obtained through research reports and technical visits. It was found in this way the lack of environmental education of the population, mainly those of low socioeconomic power installed in critical areas such as the settlements and in rural areas.
\end{abstract}

Keywords: environmental risks, Brejinho, solid waste. 


\section{INTRODUÇÃO}

Em pleno século XXI, um dos maiores desafios relacionados ao meio ambiente com que se defronta a sociedade moderna é o equacionamento da questão dos resíduos sólidos, os grandes centros urbanos estão convivendo com uma série de problemas estruturais, e o êxodo dos habitantes, da zona rural, tem influído no seu crescimento demográfico, o que acaba agravando as condições ambientais da população. Para Puppi (1981), o afluxo, em geral imprevisto, certamente implica em sérias consequências para o planejamento urbano, não capacitado para acolher contingentes humanos maciços que buscam se sediar, criando-lhe impactos funcionais, e uma série de problemas estruturais, sociais e econômicos, alguns são novos, outros já existentes, e se agravam, vinculados à habitação, ao ajustamento ambiental e à absorção de mão de obra, de regra não qualificada, com sobrecarga funcional para os serviços públicos de abastecimento, de transporte, de água e esgotos, de assistência social e médico-hospitalar, de educação, de resíduos sólidos, e outros já precários ou deficientes.

No caso específico, Brejinho (uma pequena cidade do estado do Rio Grande do Norte) tal cenário carece de um melhor planejamento, capaz de introduzir meios racionais de ocupação do território urbano, seja pela falta de critério na legislação urbanística ou falha na formação da cidade e até mesmo da omissão dos órgãos competentes. Verdade, e que tudo isso promove o surgimento de problemas ambientais, nem sempre resolvidos a contento, salvo raríssimas áreas que recebem de caráter emergencial algum socorro, quase sempre pelo alarmante nível de insalubridade do local.

É notório que a coleta e a destinação adequada dos resíduos sólidos estão ligados primordialmente às necessidade do homem. Este precisa de tratamento adequado dos resíduos sólidos para atender suas necessidades como também, afastar-se de qualquer convivência com dejetos e imundícies os quais geram doenças e reduzem a vida.

A Política Nacional de Resíduos Sólidos conceitua o tema afirmando que resíduos sólidos são: "Resíduos nos estados sólidos e semi-sólidos, que resultam de atividade de origem industrial, doméstica, hospitalar, comercial, agrícola, de serviços e de varrição. Ficam incluídos nesta definição os lodos proveniente de sistemas de tratamento de água, aqueles gerados em equipamentos e instalações de controle de poluição, bem como determinados líquidos cujas particularidades tornem inviável o seu lançamento na rede pública de esgotos ou corpos de água, ou exijam para isto soluções técnicas e economicamente inviáveis em face da melhor tecnologia disponível" (ABNT-10.004 (2005) PL № 203 (2006).

Atualmente, os resíduos sólidos e a coleta seletiva são problemas que se agravam intensamente, passando a ser um problema mundial comprometendo assim a saúde pública dessas populações.

Em Brejinho/RN não é diferente, as consequências sócio-ambientais decorrentes do descarte inadequado dos resíduos sólido, vem causando, sérios efeitos negativos, tais como, riscos ambientais, sanitários, poluição das águas, do solo, do ar, dos rios, problemas econômicos, contaminação do lençol freático, ocasionando também uma série de problemas de ordem social, econômica, sanitária além da poluição e da contaminação do meio ambiente. Isso tudo realizado através do constante lançamento de lixo em locais indevidos e também de sua queima feita por parte da população nas áreas urbanas e rural, prejudicando toda dinâmica da qualidade ambiental 
do território. Localizada na microrregião do Agreste Potiguar, com pessoas convivendo em áreas rurais em assentamentos, sem destinação coleta de resíduos sólidos adequado, sem dúvida só se agravará cada vez mais o problema.

Em suas ruas sempre descartam resíduos sólidos, que iram rumo as residências aos rios e tantos outros destinos. São inúmeros os pontos de lançamento percebidos ao caminharmos na cidade. O lixão lá existente passou a ser o principal canal de despejo na área, sem contar a ocupação desordenada da população indigente ao seu redor, a qual deu origem a assentamentos, contribuindo ainda mais para a insalubridade do local (Jerônimo; Santiago, 2012).

Considerando a importância do tratamento adequado do lixo para a determinação da qualidade de vida da população, não há uma explicação lógica do ponto de vista ambiental que justifique a não aplicabilidade da política nacional de resíduos sólidos pelos entes públicos, bem como, a inadequada destinação das verbas municipais, que possibilitariam condições de desenvolver uma política local, baseada nas prioridades das comunidades.

O controle de qualidade ambiental está na Constituição Federal, como responsabilidade do poder público, juntamente com o despertar da conscientização social para a defesa do meio ambiente. A Carta Constitucional promulgada em 1988 (BRASIL 1988), em Capítulo próprio Capítulo VI - art. 225 sobre o meio ambiente assegura que "Todos tem direito ao meio ambiente equilibrado, bem de uso comum do povo e essencial à sadia qualidade de vida, impondo-se ao poder público e á coletividade o dever de defendê-lo e preservá-lo para as presentes e futuras gerações".

Considerando a importância do tratamento adequado do lixo para a determinação da qualidade de vida da população, não há uma explicação lógica do ponto de vista ambiental que justifique a não aplicabilidade da política nacional de resíduos sólidos pelos entes públicos, bem como, a inadequada destinação das verbas municipais, que possibilitariam condições de desenvolver uma política local, baseada nas prioridades das comunidades (Silva; Jerônimo, 2012).

Ademais, torna-se contraditório o perfil do cidadão moderno, que é um sujeito de direitos e deveres, que deveria estar capacitado politicamente a participar ativamente da vida da cidade e da comunidade.

Logo, a motivação para a proposta de trabalhar o tema: As consequências sócioambientais decorrentes do descarte inadequado dos resíduos sólidos no município de Brejinho/RN advêm da necessidade de estudo nessa área, devido a grave situação ambiental comprovadamente instalada nas sociedades, sendo imprescindível a adequação e o enfrentamento desse problema, observando-se a questão dentro da contextualização históricosocial-econômico-cultural do município.

Este estudo visa acentuar uma visão crítica da atual realidade dos resíduos sólidos no Brasil, e mais especificamente em Brejinho/RN, apontando para sérias conseqüências na área de resíduos sólidos, no meio ambiente e na qualidade de vida da população, que sobrevive sem o destino adequado dos resíduos sólidos, ficando exposta a vários problemas de saúde, independente de classe social, uma vez que o acumulo de lixo, a céu aberto, acarretam proliferação de doenças, acúmulo de lixo, surgimento de insetos, roedores, mau cheiro, além do aspecto paisagístico desagradável, que se cria na área, considerando, também, o crescimento rápido e desordenado do município e a falta de infraestrutura para o seu desenvolvimento trazendo com isso problemas ambientais decorrentes desta expansão.

A preocupação em aprofundar o estudo sobre a questão dos resíduos sólidos, e suas conseqüências sócio-ambientais decorrentes do descarte inadequado em particular, a especificidade dessa realidade no município de Brejinho/RN, decorre, também, da grande escassez 
Rev. Elet. em Gestão, Educação e Tecnologia Ambiental (e-ISSN: 2236-1170)

de trabalhos e pesquisas voltados para esta temática em nível local, que privilegie os seguimentos excluídos desse processo.

O estudo de caso aqui tratado a cidade de Brejinho, localizada no Estado do Rio Grande do Norte, Nordeste do Brasil. O objetivo geral dessa pesquisa é mostrar o destino final dado aos resíduos sólidos desse município e a influência na vida das pessoas sem renda alguma, que sobrevivem nos seus lixões.

Existem várias autores que já vem realizando pesquisas sobre a problemática dos resíduos sólidos, entre eles destaca-se: Jerônimo; Santiago Jr (2012); Silva; Jerônimo (2012); Amorim (2010); Baratto (2010), Guanabara (2008); Felix (2007); Flick (2010); Freire (2009); Fernandes (2008); Hempe (2010), Córdula (2009); Leite (2004); Melo (2009); Oshitake (2010); Ramos (2010), Noguera (2010), Lima (2010), Scheren (2004); entre outros. Os autores nomeados tem tido como objeto de estudo: os diferentes conceitos de resíduos sólidos e lixo, as legislações estaduais e federais, as formas de disposição adotadas para os resíduos sólidos urbanos, a coleta seletiva, reciclagem e a reutilização, o ensino da educação ambiental, o uso das tecnologias nas práticas ambientais, entre outros temas.

Para a compreensão do tema, transcreve-se uma visão jurídica mais ampla de meio ambiente, que seria "a interação do conjunto de elementos naturais, artificiais e culturais que propiciem o desenvolvimento equilibrado da vida em todas as suas formas", mas em face das mais diversas mutações em torno da problemática ambiental, é necessário uma perspectiva muito ampla e atualizada dos aspectos relacionados ao meio ambiente e dentro deste contexto, o ser humano.

Neste trabalho procurara-se situar geograficamente o espaço estudado, considerando não apenas os aspectos físicos regionais, mas também os projetado através de programas governamentais para o atendimento das necessidades básicas de tratamento adequado aos resíduos sólidos. Analisando quantitativamente as características da população alvo deste tipo de atendimento, através de dados estatísticos disponíveis nos órgãos responsáveis, procurando assim formalizar, um modelo hipotético da qualidade deste tipo de serviço. Por último, visualiza-se o aspecto crítico da situação, o que permitirá sugerir medidas paliativas capazes de servir como referência, no sentido de projetar mecanismos globais, susceptíveis de otimizar a qualidade deste tipo de atendimento na área.

\section{METODOLOGIA}

O objeto empírico deste trabalho de pesquisa está direcionado para as conseqüências sócio-ambientais decorrentes da ausência do tratamento inadequado aos resíduos sólidos do município de Brejinho/RN, e deverá ser analisado quanto a dinâmica do território.

Adotou-se, no decorrer da pesquisa, instrumentos e procedimentos que nos darão subsídios para concretização dos nossos objetivos, que podem sofrer mudanças, uma vez que os mesmos não são rígidos e inalteráveis.

Os instrumentos ou técnicas utilizadas na pesquisa serão: a observação sistemática, participante e individual ou em equipe, o questionário, a entrevista, levantamento de referências e fontes pertinentes á área de estudo, organização e análise dos dados para aquisição das informações relacionadas ao tema proposto. Para contribuir com o estudo e enfatizar esta questão, adota-se como metodologia, uma revisão bibliográfica, incluindo nesta, artigos, textos, materiais coletados na internet, estudo da legislação, estudos de outros autores e visita ao campo. 
Rev. Elet. em Gestão, Educação e Tecnologia Ambiental (e-ISSN: 2236-1170)

O intuito é o de acentuar uma visão crítica da atual realidade dos resíduos sólidos no Brasil (comparando-se inclusive a estudos semelhantes em municípios circunvizinhos), e mais especificamente em Brejinho/RN, apontando para sérias consequências do descarte inadequado dos resíduos sólidos, no meio ambiente e na qualidade de vida da população, que convive com o total descaso à não aplicabilidade do tratamento correto destes resíduos, ficando expostos a todos os riscos ambientais, independente de classe social, uma vez que o lixo a céu aberto, acarreta inundações, proliferação de doenças, mau cheiro, contaminação das águas, problemas sociais, mortandade de animais silvestres, além do aspecto paisagístico desagradável, que se cria na área. Observou-se, também, qual a relevância que o crescimento desordenado do município e a falta de infraestrutura para o seu desenvolvimento influência nos problemas ambientais.

A preocupação em aprofundar o estudo sobre a questão dos resíduos sólidos, e suas consequências sócio-ambientais enquanto política pública, em particular, a especificidade dessa realidade na área urbana de Brejinho, decorre, também, da grande escassez de trabalhos e pesquisas voltados para a temática em nível local, que privilegie os segmentos excluídos desse processo.

Inicialmente, pretende-se realizar um levantamento através de questionário aberto, para identificar a situação física, ambiental e social da população, e a expectativa destes, em relação à questão da política ambiental, proposta pelo Estado, como também discutir as implicações e responsabilidade do poder público.

Outra forma de coletar dados foi a realização aleatória de entrevistas informais com a população, objetivando verificar qual o conhecimento e aceitação destes, no processo de tratamento de resíduos sólidos, decorrente de políticas públicas desenvolvida em Brejinho - RN. Também com os representantes das associações comunitárias, escolas, posto de saúde, agentes de saúde e lideranças locais, serão alvo de nossas entrevistas informais, verificando o que acarreta ao cotidiano do bairro, o tratamento dado aos resíduos sólidos.

Após o arrolamento dos dados, serão selecionados, seguindo-se interpretação e análise dos mesmos, procurando encadear os elementos teóricos trabalhados. Ato contínuo onde buscaremos, analisar os resultados obtidos com a pesquisa junto aos usuários que não são atendidos pelo sistema da coleta de resíduos sólidos, possibilitando a eles se auto-avaliarem diante da situação-problema, onde procuraremos alternativas de soluções para o acesso ao serviço a que todos precisam para assegurar o bem-estar físico, mental e social, a que tem direito.

As atividades de campo foram executadas durante os meses de abril a agosto de 2012, por uma equipe multidisciplinar, do Instituo de Desenvolvimento e Meio Ambiente do Rio Grande do Norte - IDEMA, que realizava um projeto de educação ambiental no município de Brejinho/RN.

\section{Caracterização do Município}

Brejinho, município no estado do Rio Grande do Norte (Brasil), localizado na microrregião do Agreste Potiguar. De acordo com o censo realizado pelo IBGE (Instituto Brasileiro de Geografia e Estatística) no ano 2000, sua população era de 10.317 habitantes. Estimativas do mesmo instituto no ano de 2005 indicam uma população de aproximadamente 11.748 habitantes. Área territorial de $59 \mathrm{~km}^{2}$. Limita-se com os municípios de Monte Alegre (norte), Jundiá (leste), Passagem (sul) e Santo Antônio e Lagoa de Pedras (oeste). A localização geográfica pode ser visualizada na Figura 1. 


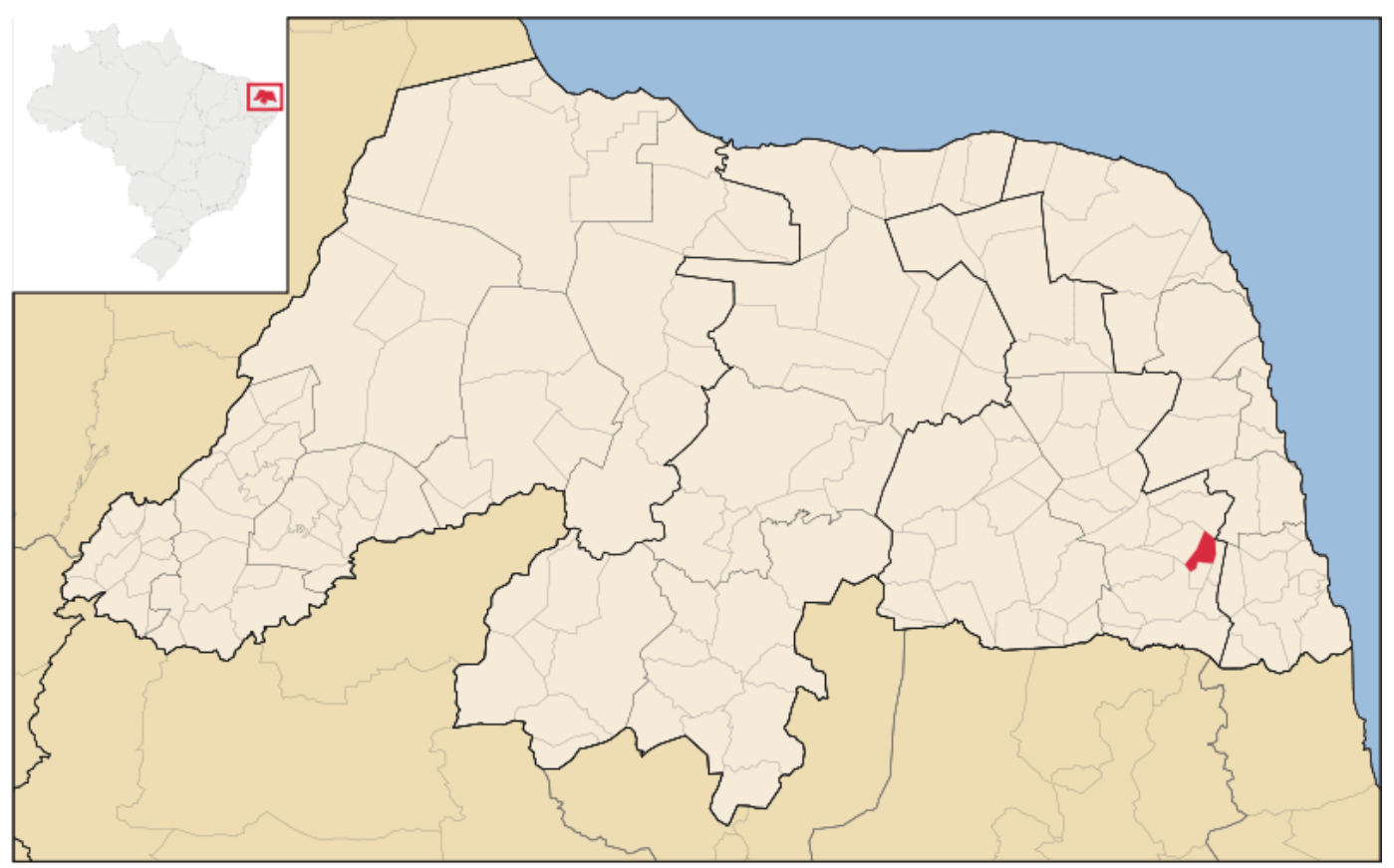

Figura 1. Mapa de localização do município de Brejinho/RN.

\section{RESULTADOS E DISCUSSÃO}

No Estado do Rio Grande, as questões relacionadas aos resíduos sólidos estão sob a responsabilidade das Prefeituras, tendo esta o domínio e estrutura necessária para a implantação do plano de resíduos sólidos em sua totalidade. No entanto, o percentual da população beneficiada com o serviço de tratamento de resíduos sólidos, é infinitamente menor com relação aos que se encontram prejudicados pela ausência de uma política pública de inclusão social voltada precisamente aos aterros sanitários.

Como visto o destino correto dado aos resíduos sólidos exerce uma posição preponderante no cotidiano da população, uma vez que esse ato ajuda a preservar a saúde do homem no seu mais amplo sentido, gerando o bem-estar físico, mental. Sua área de atuação é vasta, tendendo a crescer devido à necessidade de controle sobre o de agir do homem no meio ambiente. Nessa projeção é relevante investir em um estudo que contribua para a discussão de uma política pública de inclusão social em nível local, que venha a atender as necessidades da população, diante dos entraves político-ideológicos existentes por partes dos governos, face à questão.

A Constituição Brasileira de 1988 abordou com maior ênfase as questões ambientais, considerando o meio ambiente como patrimônio nacional e das futuras gerações. Nesta Carta Magna, o resíduo sólido foi considerado como destaque, recomendando-se maior fiscalização e ação dos órgãos públicos e privados responsáveis pelo setor.

Constituição Federal de 1988: consta nos artigos 21, 23 e 200:

Art. 21. Compete à União:

[..]

$X X$ - instituir diretrizes para o desenvolvimento urbano, inclusive habitação, saneamento básico e transportes urbanos;

Art. 23. É competência comum da União, dos Estados, do Distrito Federal e dos Municípios: http://cascavel.ufsm.br/revistas/ojs-2.2.2/index.php/reget 
Rev. Elet. em Gestão, Educação e Tecnologia Ambiental (e-ISSN: 2236-1170)

[..]

IX - promover programas de construção de moradias e a melhoria das condições habitacionais e de saneamento básico;

Art. 200. Ao sistema único de saúde compete, além de outras atribuições, nos termos da lei:

[..]

IV - participar da formulação da política e da execução das ações de saneamento básico;

As legislações que contemplam os resíduos sólidos situam-se, também, nas políticas nacionais e legislações ambientais, destacando-se: Política Nacional de Meio Ambiente: Lei no 6.938 de 31/08/1981. Política Nacional de Saúde: Lei Orgânica de Saúde no 8.080 de 19/09/1990. Política Nacional de Recursos Hídricos: Lei no 9.433 de 08/01/1997. Lei de Crimes Ambientais: Lei no 9.605 de 12/02/1998. Estatuto das cidades: Lei no 10.257 de 10/07/2001. Política Nacional de Saneamento Básico: Lei no 11.445 de 05 de janeiro de 2007.

Desta forma, procurou-se, através dos resultados obtidos com a pesquisa, desvelar e refletir sobre o tema: as consequências sócio-ambientais decorrentes do descarte inadequado dos resíduos sólidos no município de Brejinho/RN, e empreitar discussão sobre as responsabilidades do poder público com a implementação de uma política ambiental que defenda o tratamento desses resíduos como um meio de atender à população no processo de melhoria do meio ambiente e consequentemente, da qualidade de vida.

A análise das consequências sócio-ambientais decorrentes da falta de tratamento dos resíduos sólidos no município de Brejinho será realizada sob a ótica da investigação científica, avaliando todos os atores envolvidos, onde pretendemos fazer um estudo crítico dessa situação, especificamente dos materiais reciclados, envolvendo seus aspectos históricos, estruturais, políticos, ideológicos e sua subutilização.

Conforme contato com a população no Município não existe aterro controlado, o Município dispõe os seus resíduos em lixão, provocando com isso sérios danos ambientais, tais como: alterar a qualidade de ar em função das emanações de gases e poeiras, poluição das águas superficiais e do subsolo pelo derramamento do chorume, agressão estética ao solo devido o espalhamento de lixo, atrair diversos vetores causadores de enfermidades, como por exemplo, ratos, moscas, urubus, baratas e outros. A presença de catadores trabalhando sem equipamentos de proteção individual neste ambiente insalubre e degradante com relação a condição humana também é outro problema. O local utilizado para a destinação dos resíduos pode ser observada nas Figuras 2 e 3. 
Rev. Elet. em Gestão, Educação e Tecnologia Ambiental (e-ISSN: 2236-1170)

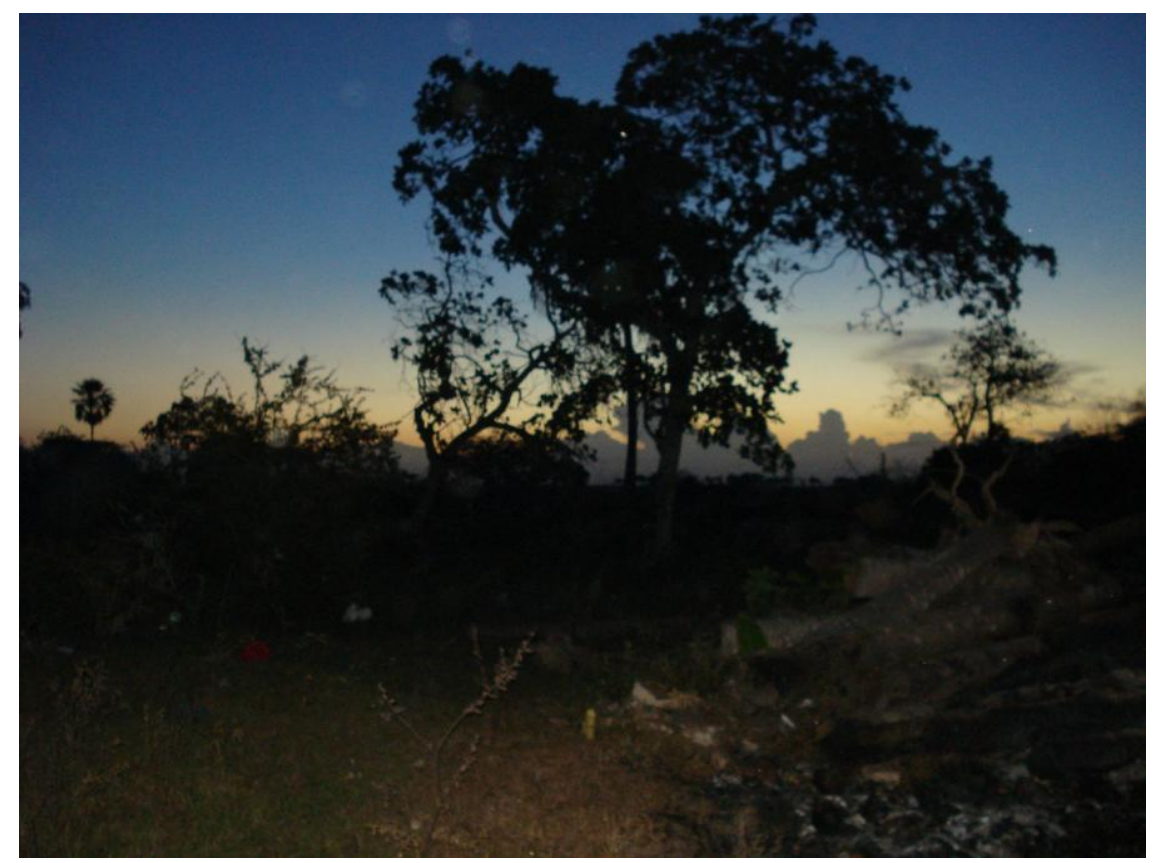

Figura 2. Vista Noturna da área de destinação dos resíduos sólidos em Brejinho/RN.

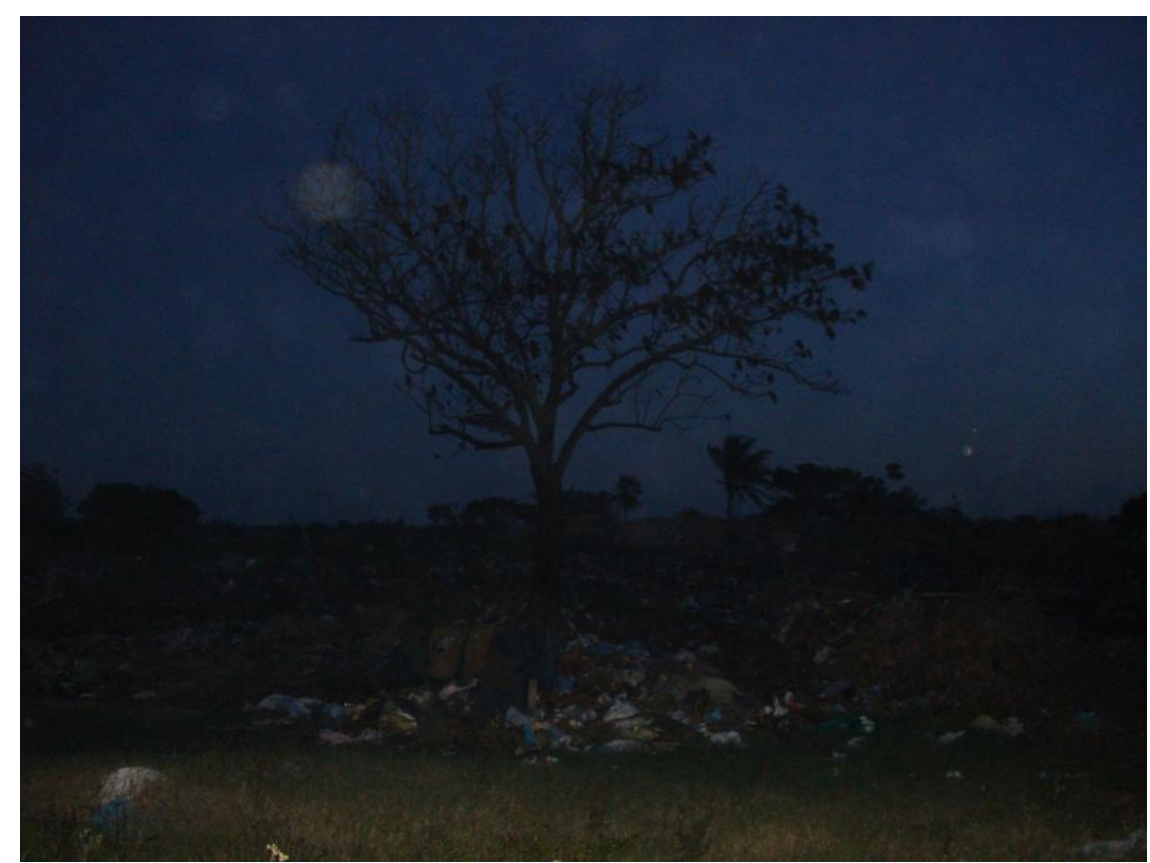

Figura 3. Vista Noturna da área de destinação dos resíduos sólidos em Brejinho/RN.

O cenário observado é afeto ao apresentado por Silva; Jerônimo (2012) para o município de Bom Jesus/RN e por Jerônimo; Santiago Jr (2012) para o município de Espírito Santo/RN. Tal tendência descreve que o padrão adotado na política pública destes municípios tende a ignorar as questões sócio-ambientais. Sobretudo, não adotando medidas mitigadoras e nem projetos técnicos adequados para um descarte correto dos seus resíduos sólidos.

Nos três municípios mencionados não existe coleta seletiva de resíduos, logo, o local de destinação sofre com uma sobrecarga no volume de resíduos destinados. Nos três casos, entretanto, não são observados um número representativo de catadores de resíduos. 
Rev. Elet. em Gestão, Educação e Tecnologia Ambiental (e-ISSN: 2236-1170)

\section{CONCLUSÃO}

Tendo em vista o que foi exposto, aponta-se como solução para o problema do descarte inadequado dos resíduos sólidos do município de Brejinho/RN a construção de um aterro sanitário, atendendo com isso as normas ambientais e oferecendo benefícios sociais, uma vez que não comportaria a presença de catadores que atualmente vivem nos lixões.

Diante desse cenário, faz-se necessário ainda a adoção de medidas que vão desde a adequada aplicação de políticas públicas, bem como, um maciço investimento em programas de educação ambiental dos entes envolvidos, para que seja possível atrelar desenvolvimento com comprometimento ambiental.

A relevância desse tema encontra respaldo na prioritária necessidade de tratarmos a questão não apenas sob a ótica ambiental, mas também e principalmente, na perspectiva social, pois envolvem questões de saúde pública, o que diretamente afeta a própria qualidade de vida da população.

A nossa caminhada em direção a Política Nacional de Resíduos Sólidos está apenas começando e ainda precisa de longo amadurecimento: É grande a dificuldade fazer cumprir as leis em nosso país, sobretudo, as ambientais que ainda são de pouco conhecimento social. Vemos ainda, as lacunas nas leis ambientais de resíduos sólidos. Os legisladores deveriam sempre realizar debates com a sociedade e com pesquisadores ou cientistas da área, antes de textualizar uma lei, para que esta seja completa.

A maior parte das pessoas que utilizam os equipamentos eletroeletrônicos ou baterias de celulares, não tem noção do prejuízo que estes produtos podem fazer no meio ambiente. 0 tempo de vida dos equipamentos reduziu nos últimos anos, assim como, seus custos. Vivemos em uma sociedade mais consumista, e as pessoas estão sempre a substituir os equipamentos gerando, com isto, mais resíduos. Mas apesar de tudo isto, temos leis que foram marcos importantes para o Brasil, como a resolução CONAMA 05/93, que classifica os resíduos de saúde segundo o risco e dar atribuições a vários agentes envolvidos - os geradores, autoridades sanitárias e ambientais. A educação ambiental através da mídia falada ou escrita, nas escolas e nas empresas, além de uma fiscalização mais atuante, contribuiria, para aumentar a conscientização ambiental e o senso do bem comum.

\section{REFERÊNCIAS}

ABRELPE - Associação Brasileira de Empresas de Limpeza Pública e Resíduos Especiais. Panorama dos resíduos sólidos no Brasil. 2005. Disponível em: HTTP://www.abrelpe.com.br/panorama_2005..php. Acesso em: 18 abril.2012.

ANTUNES, R. Adeus ao trabalho? : ensaio sobre as meta-morfoses e a centralidade do mundo do trabalho. 6 . ed. Campinas, SP. Cortez, 1995.

ASSOCIAÇÃO BRASILEIRA DE NORMAS TÉCNICAS. Resíduos sólidos - classificação: NBR-10004. Rio de Janeiro: ABNT , 2004.63p. [se optar por incluir o numero de páginas nas referencias, precisa por em todas elas; adotamos o ano no final das referencias]

BARROS, V. A; SALES M. M. \& NOGUEIRA, M. L. M. (2002) Exclusão, favela e vergonha: uma interrogação ao trabalho. In: GOULART, I. B. (Org.). Psicologia organizacional e do trabalho: teoria, pesquisa e temas correlatos. São Paulo: Casa do Psicólogo, 2002. p.xx-xx [neste caso de parte de livro, as páginas inicial e final da parte são obrigatórias]

BORGES, A. F; GOULART, I. (Ed.). Psicologia Organizacional e do Trabalho: teoria, pesquisa e temas correlatos. São Paulo. Casa do Psicólogo, 2002.

BRASIL. Constituição (1988). Constituição da República Federativa do Brasil. Brasilia, DF, Senado, 1988.

BRASIL. Ministério da Educação. Secretaria de Educação Fundamental. Parâmetros Curriculares Nacional. Brasilia, 1998. 
Rev. Elet. em Gestão, Educação e Tecnologia Ambiental (e-ISSN: 2236-1170)

BRASIL. Senado Federal. Agenda 21 Conferência das Nações Unidas sobre o meio ambiente e desenvolvimento. 3 ed. [Faltam elementos nesta referencia?]

CALDERONI, S. Os bilhões perdidos no lixo. 4. ed. São Paulo: Liv.Humanistas - FFCH/USP, 2005. 346 p.

CODO, W. Indivíduo, trabalho e sofrimento: uma abordagem interdisciplinar. Petropolis, RJ: Vozes, 1993.

DEJOURS, C. A banalização da injustiça social. 4. ed. Rio de Janeiro, RJ: FGV, 1999.

FELIZ, R. A. Z. Coleta seletiva em ambiente escolar. Revista Eletrônica do Mestrado em Educação Ambiental. São Paulo. v.18 p.56-71, 2007. Disponível em : http://www.remea.furg.br .Acesso em: 20 dez. 2009.

GONZALES, T. V; REIS, M. F. C. T; DINIZ, R. E. S. Educação ambiental na comunidade: uma proposta de pesquisa-ação. Revista Eletrônica do Mestrado em Educação Ambiental, São Paulo. v. 18, janeiro-junho, 2007. Disponível em; http://www.remea.furg.br acesso em: 20 dez.,2009; www.agenda21.com.br Acesso em: 15 abr., 2012.

GUANABARA, R. ; GAMA, T. ; EIGENHEER, E. M. Os resíduos sólidos como tema gerador: da pedagogia dos três R's ao risco ambiental. Revista Eletrônica do Mestrado em Educação Ambiental .v.21, jul-dez, 2008.

JACOBI, P. Educação Ambiental Cidadania e Sustentabilidade. Ed. Cortez. São Paulo, 2003.

JERONIMO, C. E. M.; SANTIAGO JR, A. F. desafios da administração ambiental publica: estudo de caso do município de Espírito Santo/RN. Revista de Administração de Roraima. Ed. 2. Vol. 1. p. 136-146. 2012.

LOPES, I.V. Filho, G. S. B, Biller, D. \& Bale, M. Gestão ambiental no Brasil, experiência e sucesso. Ed. Fundação Getúlio Vargas. Rio de Janeiro, 1996.

MEIRELLES, S. A. A explosão urbana - Revista Ecologia e Desenvolvimento, 2001.

MEKSENAS, P. Cidadania, Poder e Comunicação. Ed. Cortez. São Paulo, 2002.

MINISTÉRIO DO MEIO AMBIENTE. Legislação. http://www.mma.gov.br/sitio/index.php?ido=legislacao.index\&tipo=0>. Acesso em: 12 jul., 2011.

MORIN, Edgar, Ciências com consciência. Rio de Janeiro. Ed. Bertrand Brasil, 2000.

NOVAIS, Maurício. Opulência e pobreza: causas e conseqüências da degradação sócio-ambiental. Instituto Ethos, São Paulo, 2008. www.ethos.org.br. Acesso em 29 abr.2012.

REIGOTA, Marcos. O que é educação ambiental. São Paulo: Brasiliense, 2006.

REIS, E. J. \& MOTA, R. S. The application of economic instruments in environmental policy: The Brazilian case. Revista Brasileira de Economia. Rio de Janeiro, 48(4): pp. 551-75.

RIZZO, Marçal. Rogério. O consumismo, o meio ambiente e a violência. Local: Editor, 2008.

SALDANHA, C. J., Sociedade, meio ambiente, políticas públicas e a erradicação de velhas práticas. Artigo. Jornal da Ciência, 13/07/2009.

SANCHEZ, L. E. Avaliação de Impacto Ambiental: conceitos e métodos. Oficina de Textos. São Paulo, 2008.

SANTOS, M. Da Totalidade do lugar. 1ạ Ed. Editora da Universidade de São Paulo, São Paulo, 2008.

SILVA, S. A.; JERÔNIMO, C. E. M. Educação ambiental, uma questão de "sobrevivência": estudo de caso para o município de Bom Jesus/RN. REMOA. v(9), no 9, p. 1992 - 2009, 2012.

SILVA-SANCHEZ, S. S. Cidadania ambiental: novos direitos no Brasil. Annablume/Humanitas. São Paulo, 2000.

VIANA Jr., A. Paper apresentado no seminário "Populações, Territórios e Recursos Naturais", Instituto de Estudos Amazônicos e Ambientais (IEA), 1994.

VININHA, F. C. Ecoturismo e Preservação ambiental. Artigo publicado em 29/jul/2004. Jornalista e Diretora da Revista Ecotour. Internet, acesso em 10/jul/2012.

WEBER, A. N. et al. Políticas Públicas em Biodiversidade: Conservação e uso Sustentado no País da Megadiversidade. Artigo Científico. 16/07/2009. 